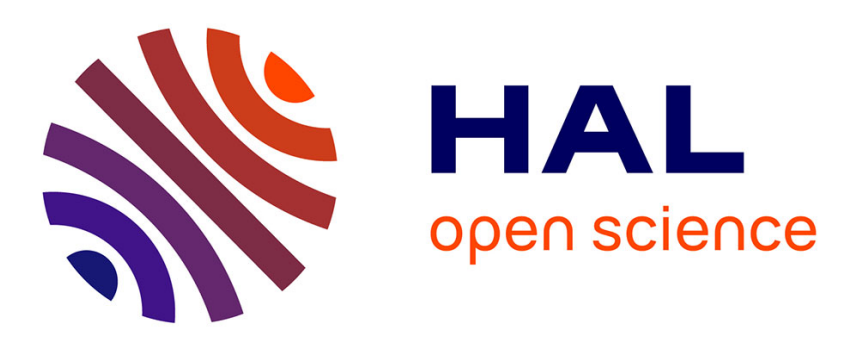

\title{
A real time neutron scattering experiment for the study of polymer dynamics
}

\author{
François Boué, M. Nierlich, G. Jannink, R.C. Ball
}

\section{To cite this version:}

François Boué, M. Nierlich, G. Jannink, R.C. Ball. A real time neutron scattering experiment for the study of polymer dynamics. Journal de Physique Lettres, 1982, 43 (16), pp.585-591. 10.1051/jphyslet:019820043016058500 . jpa-00232095

\section{HAL Id: jpa-00232095 https://hal.science/jpa-00232095}

Submitted on 1 Jan 1982

HAL is a multi-disciplinary open access archive for the deposit and dissemination of scientific research documents, whether they are published or not. The documents may come from teaching and research institutions in France or abroad, or from public or private research centers.
L'archive ouverte pluridisciplinaire HAL, est destinée au dépôt et à la diffusion de documents scientifiques de niveau recherche, publiés ou non, émanant des établissements d'enseignement et de recherche français ou étrangers, des laboratoires publics ou privés. 


\title{
LE JOURNAL DE PHYSIQUE-LETTRES
}

J. Physique - LETTRES 43 (1982) L-585 - L-591

15 AOÛT 1982, PAGE L-585

Classification

Physics Abstracts

$05.40-46.30 \mathrm{~J}-61.12-61.40 \mathrm{~K}-05.90$

\section{A real time neutron scattering experiment for the study of polymer dynamics}

\author{
F. Boué, M. Nierlich, G. Jannink and R. C. Ball \\ Laboratoire Léon Brillouin, C.E.N. Saclay, 91191 Gif sur Yvette Cedex, France
}

(Reçu le 11 février 1982, accepté le 21 juin 1982)

\begin{abstract}
Résumé. - On étudie la dynamique d'un polymère fondu (polystyrène amorphe) de longues chaînes $\left(M_{w}=650000\right)$ en observant à des instants successifs le facteur de forme statique de la chaîne pendant la relaxation, à longueur fixée, d'un échantillon préalablement étiré uniaxialement. Cette lettre présente des données de diffusion de neutrons aux petits angles pour une série de valeurs de la durée de la relaxation qui sont environ égales, ou supérieures au temps de Rouse de la chaîne. Les données de cette expérience couvrent tout le domaine submoléculaire du vecteur de diffusion, grâce à la combinaison de trois configurations différentes des spectromètres. Une discussion plus complète de la dépendance en temps du facteur de forme est maintenant possible. Une contribution à cette discussion est apportée dans la lettre suivante.
\end{abstract}

\begin{abstract}
The dynamics of an amorphous polystyrene $\left(M_{\mathrm{w}}=650000\right)$ melt is studied by successive observations of the static coil form factor during stress relaxation following a uniaxial deformation. This paper presents neutron scattering data for a duration of relaxation of the order of, or bigger than the Rouse time of the chains. The data cover the entire submolecular range for the scattering vector, as the result of the successive use of three different spectrometer configurations. A more complete discussion of the time dependence of the static form factor is now possible. A contribution to this discussion is given in the next letter.
\end{abstract}

1. Introduction. - By a real time experiment we mean successive instantaneous measurements of observables in a time dependent system.

The measured quantity is the static coil form factor obtained by small angle neutron scattering in the static approximation. Because the time required for such a measurement is long compared to the characteristic time of the system, we quench the sample for each observation. The sample is a strip of polystyrene (atactic, blend of normal polystyrene, $M_{\mathrm{wH}}=760000$, and perdeuterated polystyrene, $M_{\mathrm{w}}=680000, M_{\mathrm{w}} / \dot{M}_{\mathrm{n}} \lesssim 1.3$ ) [2], suddenly stretched [3] by a factor 3 at a temperature $T_{\mathrm{s}}>T_{\mathrm{g}}$ (glass transition temperature) and maintained at a constant elongation. The stress relaxes while the sample returns to equilibrium, and it is observed at different states of relaxation 
defined by the duration of relaxation $t_{\mathrm{R}}$ following the deformation. The strip is quenched at $t_{\mathrm{R}}$ and, subsequently, brought in front of the neutron beam of a small angle scattering spectrometer of the high flux reactor of the Institute von Laue Langevin, Grenoble (France). We assume that the configurations of the coils are not modified by quenching [4], only frozen.

The control of the experiment is difficult but results are now reproducible. This is discussed in reference [1], together with the variation of the transverse radius of gyration and the variation of the form factor in the submolecular range of the scattering vector $q$. The range of scattering vectors in which the static coil form factor has been measured was however limited to the interval $\left[7 \times 10^{-3}, 2 \times 10^{-2} \AA^{-1}\right]$. Since that time, by using successively three different configurations for the spectrometers at the Institute von Laue Langevin, this form factor has been measured in the largest possible scattering vector interval covering the submolecular domain, $\left[7 \times 10^{-3}\right.$, $\left.1.5 \times 10^{-1} \AA^{-1}\right]$.

This interval, controlling the scattering experiment, is defined with respect to the characteristic lengths associated with the polystyrene coils. We consider here data corresponding to the orientations of q parallel (subscript $\|$ ) and perpendicular (subscript $\perp$ ) to the uniaxial direction.

2. Order of magnitude of polymer inverse characteristic lengths. - A typical length is the radius of gyration $R_{\mathrm{g}}$. In the isotropic, totally relaxed, state, the radius is for our sample

$$
R_{\mathrm{g}_{\text {iso }}} \simeq 250 \AA \text {. }
$$

The affine value for the quantity corresponding to the elongation 3 , are

$$
\begin{aligned}
& R_{\mathrm{g} \perp}=250 / \sqrt{3} \\
& R_{\mathrm{g} \|}=250 \times 3 .
\end{aligned}
$$

We have checked in reference [1] the validity of the affine deformation immediately after deformation using data in perpendicular direction. Another characteristic length is often proposed in the discussion of polymer melts, although its existence is very questionable. It is the diameter $D$ of the fixed tube in which a coil is constrained to move during a time interval equal to $T_{\text {Rouse }}$. It is often written :

$$
D=R_{\mathbf{g}_{\mathrm{iso}}} \sqrt{\left(N_{\mathrm{e}} / N\right)}
$$

where $N$ is the number of statistical units of the chains and $N_{\mathrm{e}}$ is a number of units such as chains with $N>N_{\mathrm{e}}$ show, for various physical quantities observed by various techniques, a behaviour different from that of smaller chains. Depending on the technique, one obtains [7] :

$$
100<N_{\mathrm{e}}<1000 \text { which implies } 25 \AA<D<90 \AA .
$$

A third characteristic length is here the size of the monomer

$$
a=2.5 \AA \text {. }
$$

Table I shows the characteristics of the three configurations of the two small angle neutron scattering spectrometers used in our experiment to cover the whole range $\left[7 \times 10^{-3} \AA^{-1}\right.$, $\left.2 \times 10^{-1} \AA^{-1}\right]$.

From figure 1 it appears that the experiment is suitable to obtain data in the asymptotic range defined by

$$
q_{\|} R_{\mathrm{g} \|} \geqslant 4
$$


Table I.

\begin{tabular}{|c|c|c|c|c|c|}
\hline $\begin{array}{l}\text { Scattering } \\
\text { vector range } \\
\left(\AA^{-1}\right)\end{array}$ & Spectrometer & $\begin{array}{l}\text { Sample } \\
\text { detector } \\
\text { distance }\end{array}$ & Wavelength & $\begin{array}{l}\text { Wavelength } \\
\text { resolution }\end{array}$ & $\begin{array}{l}\text { Angular } \\
\text { collimation } \\
\text { (rad.) }\end{array}$ \\
\hline- & - & - & - & - & - \\
\hline $7 \times 10^{-3}, 2 \times 10^{-2}$ & D11 & $10 \mathrm{~m}$ & $10 \AA$ & $9 \%$ & $5 \times 10^{-3}$ \\
\hline $10^{-2}, 6 \times 10^{-2}$ & D17 & $3 \mathrm{~m}$ & $13 \AA$ & $10 \%$ & $7 \times 10^{-3}$ \\
\hline $6 \times 10^{-2}, 2 \times 10^{-1}$ & D11 & $2 \mathrm{~m}$ & $5.4 \AA$ & $9 \%$ & $10^{-3}$ \\
\hline
\end{tabular}

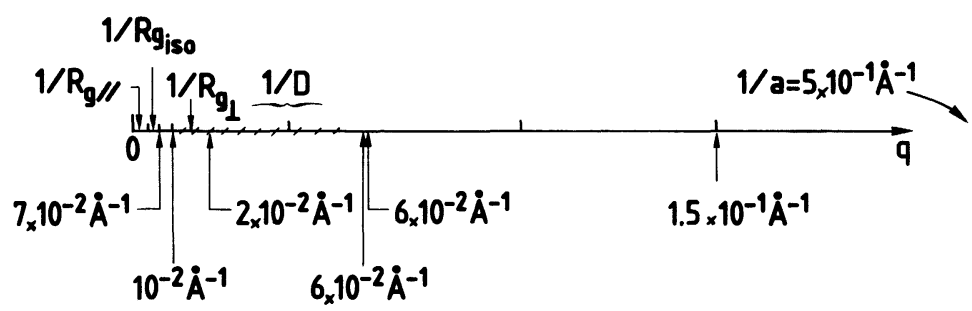

Fig. 1. - Representation of the reciprocal space intervals explored in the three spectrometer configurations used in our experiment (see Table I). The inverse characteristic lengths of the coils, discussed in this letter, are also shown.

Further, we notice that, if the ratio $N / N_{\mathrm{e}}$ is sufficiently large, this asymptotic range can be divided in two subranges $q D<1$ and $q D>1$. Therefore, if the quantity $D$ should have an effect on the observable, then this effect could be detected.

3. Order of magnitude of times. - Data are gathered at several durations of relaxation $t_{\mathrm{R}}$. This value $t_{\mathrm{R}}$ is in fact controlled by the time interval between deformation and quenching. It will be convenient to compare $t_{\mathrm{R}}$ to characteristic times of the system. Theoretical quantities are proposed such as Rouse time, $T_{\text {Rouse }}$, and reptation time $[5,6], T_{\text {rep. }}$. The times are not presently measured experimentally ; we use an evaluation [7] of $T_{\text {Rouse }}$ from viscosity measurements at low molecular weights to evaluate $T_{\text {Rouse }}\left(\alpha N^{2}\right)$ for $M_{\mathrm{w}}=650000$. We evaluate $T_{\text {rep }}$ from the experimental values of terminal relaxation time at this molecular weight [7]. These evaluations are displayed and discussed in reference [1] (written as $T_{\text {eq }}$ for $T_{\text {Rouse }}$ and $T_{\text {dis }}$ for $T_{\text {rep }}$ ). They are strongly dependent upon temperature, $\mathbb{T}$. We assume a Williams Landel Ferry temperature dependence [7] :

with

$$
\underset{\text { (rep) }}{T_{\text {Rouse }}(\mathbb{T})=\frac{a_{\mathbf{T}}}{a_{\mathbf{T}_{0}}} T_{\text {rep }}}\left(\mathbb{T}_{0}\right)
$$

$$
\log _{10} a_{\mathrm{T}}=\frac{1744(\mathrm{~T}-100)}{50+\mathbb{T}-100}
$$

The temperatures used for stretching the melt in our experiment are $113{ }^{\circ} \mathrm{C}, 117^{\circ} \mathrm{C}, 122{ }^{\circ} \mathrm{C}, 128^{\circ} \mathrm{C}$ and $134^{\circ} \mathrm{C}$. But we discuss here data obtained at $128^{\circ} \mathrm{C}$ and $134^{\circ} \mathrm{C}$. These temperatures are chosen because they allow exploration of a time domain in which

$$
1 \leqslant t_{\mathrm{R}} / T_{\text {Rouse }} \leqslant T_{\text {rep }} / T_{\text {Rouse }}
$$


Table II. $-S_{t_{\mathbf{R}}}(q)$, perpendicular direction.

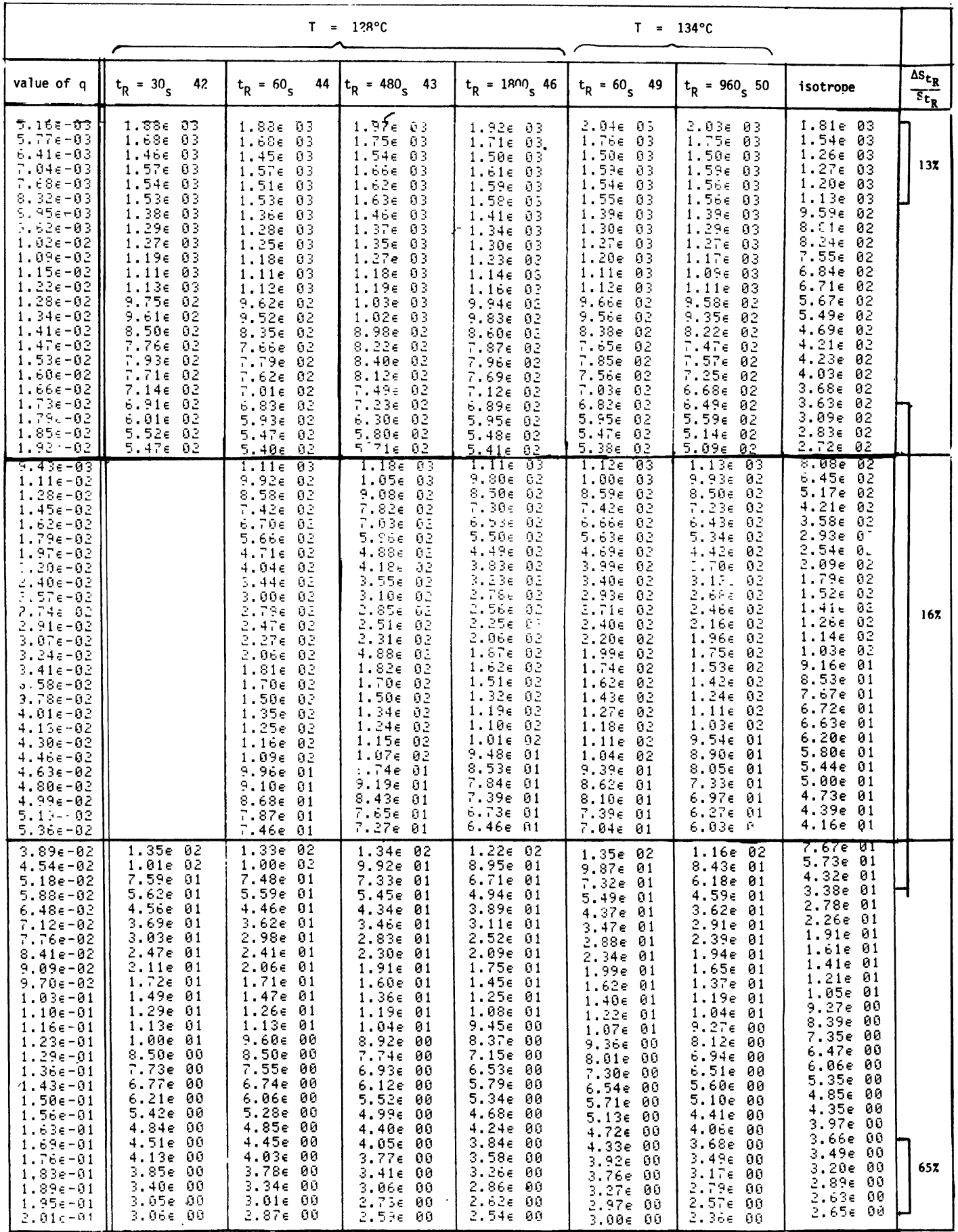


Table II (suite). $-S_{t_{\mathbf{R}}}(q)$, parallel direction.

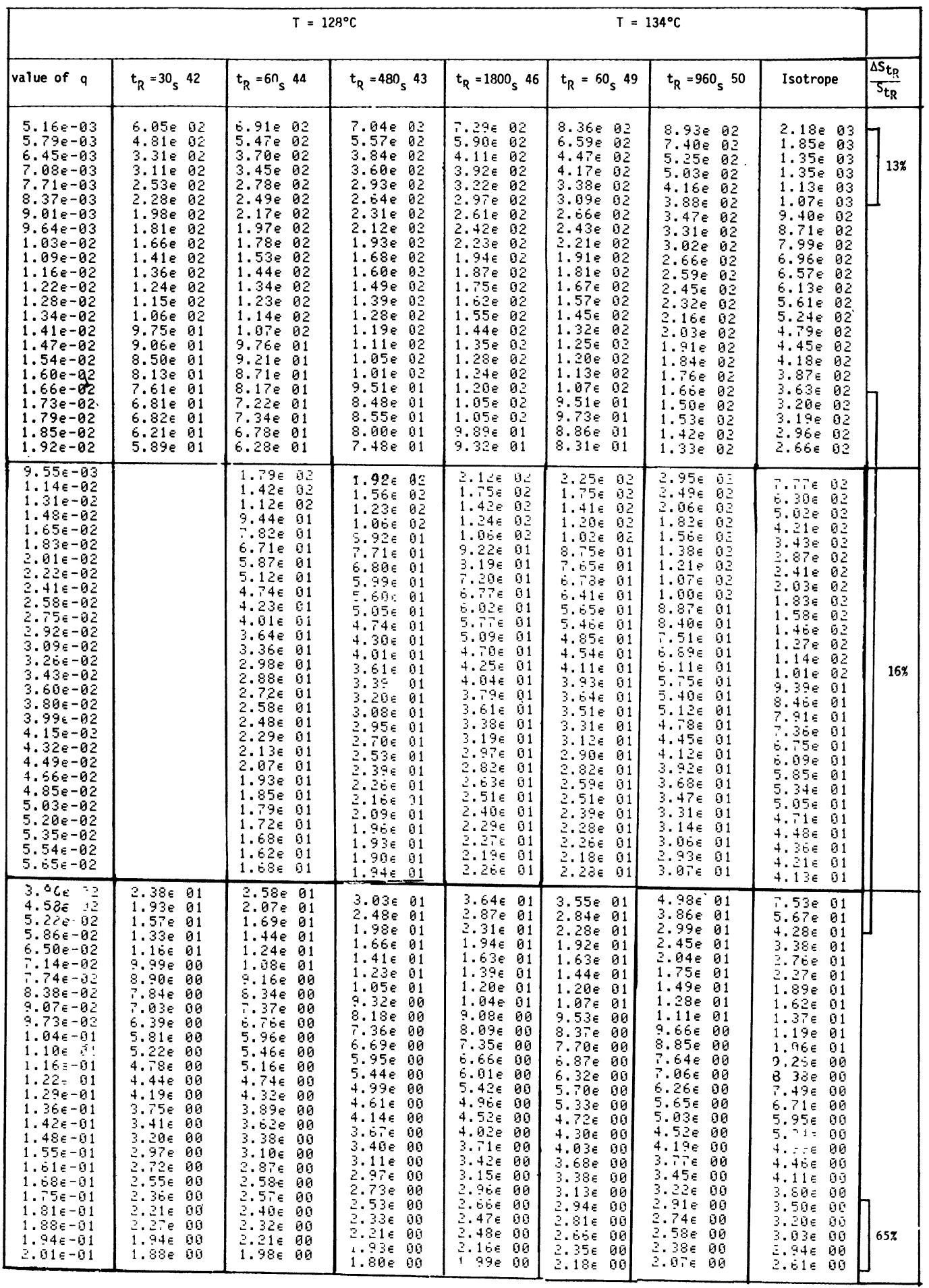


To verify (4), one can use the values of $T_{\text {Rouse }}$ and $T_{\text {rep }}$ tabulated in reference [1] for $117^{\circ} \mathrm{C}$. Using (2), (3) we obtain :
at $128^{\circ} \mathrm{C}: 150 \mathrm{~s}<T_{\text {Rouse }}<1500 \mathrm{~s}, 15000 \mathrm{~s}<T_{\text {rep }}<150000 \mathrm{~s}$
at $134^{\circ} \mathrm{C}: 60 \mathrm{~s}<T_{\text {Rouse }}<600 \mathrm{~s}, 6000 \mathrm{~s}<T_{\text {rep }}<60000 \mathrm{~s}$

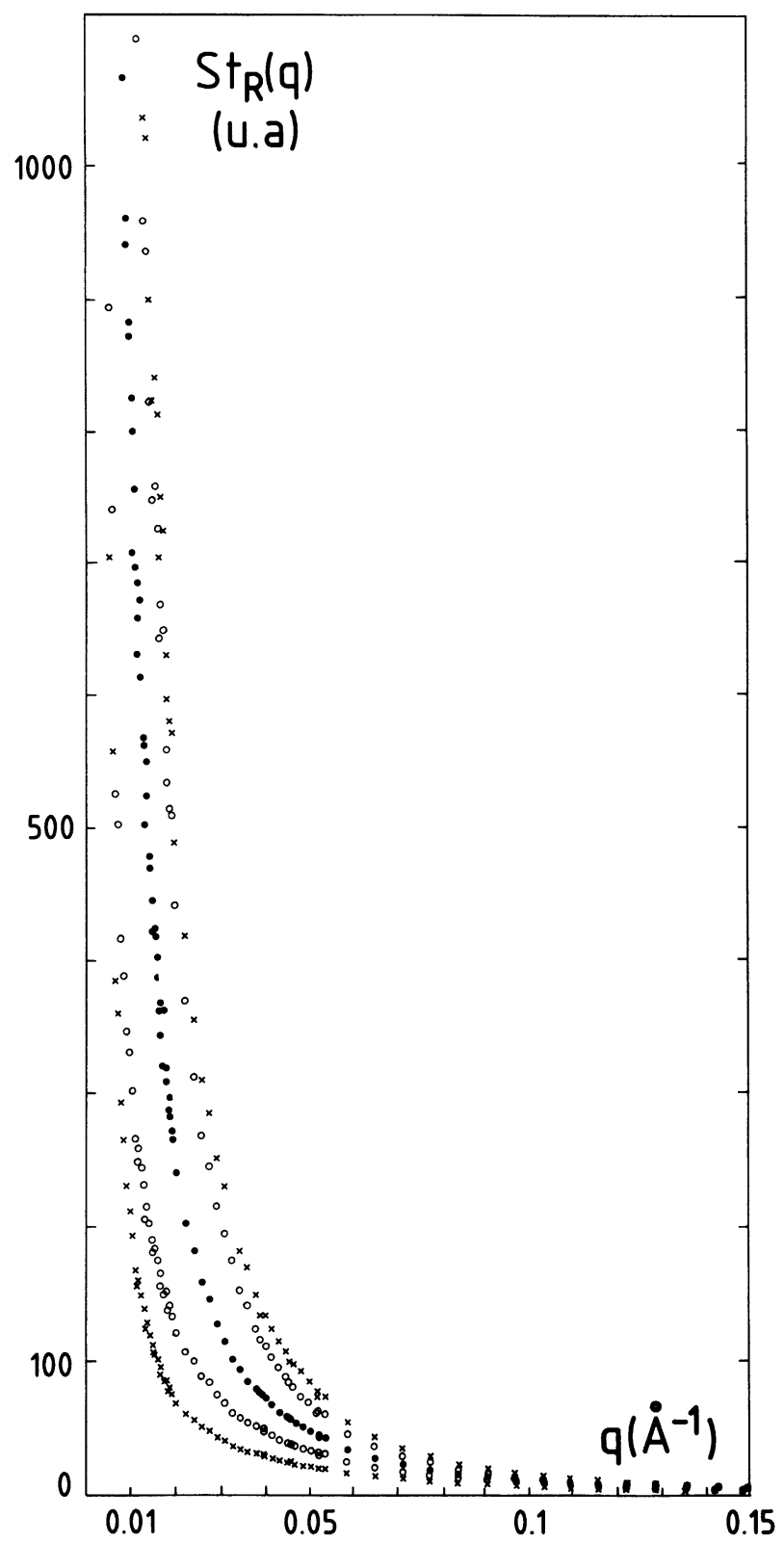

Fig. 2. - Representation of the measured static form factors $S_{t_{\mathrm{R}}}(q)$ versus the scattering vector $q$, for samples $50(O), 43(\times)$ and the isotropic sample ( () , in both directions perpendicular and parallel to the stretching. For each anisotropic sample, values of $S_{t_{\mathbf{R}}}$ measured in the perpendicular (parallel) direction are above (below) the values corresponding to the isotropic sample. 
values which can be compared to the duration of relaxation of our samples :

$$
\begin{aligned}
& \text { at } 128^{\circ} \mathrm{C}: t_{\mathrm{R}}=30 \mathrm{~s}, 60 \mathrm{~s}, 480 \mathrm{~s}, 1800 \mathrm{~s} \\
& \text { at } \underline{134^{\circ} \mathrm{C}}: t_{\mathrm{R}}=60 \mathrm{~s}, 960 \mathrm{~s} .
\end{aligned}
$$

4. Neutron scattering data. - We now consider the reciprocal space dependence of the static coil form factors $S_{t_{\mathrm{R}}}\left(q_{\|}\right)$and $S_{t_{\mathrm{R}}}\left(q_{\perp}\right)$. These quantities are tabulated in table II for all samples stretched at $128^{\circ} \mathrm{C}$ and $134^{\circ} \mathrm{C}$. They are obtained in the following way :

- first, the direct neutron scattering signal for each sample is decreased by the amount of incoherent contribution, and the result is normalized to a unique sample thickness $(1 \mathrm{~mm})$. These two operations require a precise measurement of the thickness of the sample, which is the most important source of uncertainty. Table II gives an evaluation of the uncertainty in $S_{t_{\mathrm{R}}}$;

- second, the data collected from three different spectrometers are normalized in such a way that continuity is obtained between adjacent scattering vector ranges.

Figure 2 shows a plot of such data, versus $q$, for the isotropic sample and two stretched samples. As $t_{\mathrm{R}}$ is increasing, the form factor is relaxing back to that of the isotropic sample. From the time dependence of these form factors, the theories for the coil dynamics in the melt can now be tested. A comparison between data and theories is discussed in the following letter of this issue.

Acknowledgments. - We wish to thank the ILL for neutron beam access, R. Oberthuer, our local contact, M. Roth, A. and M. Bentley and M. Cruz for their help on D17. We gratefully acknowledge helpful discussions with P. G. de Gennes, and T. Springer. We thank J. des Cloizeaux for useful comments on the manuscript.

\section{References}

[1] Bouḱ, F., Nierlich, M., Jannink, G., Ball, R., J. Physique 43 (1982) 137-148.

[2] Perdeuterated PS : P. ReMPP, CRM, Strasbourg (ref. SD 2440);

Non/deuterated PS : D. LeNFANT, EAHP, Strasbourg (ref. S572).

[3] Temperature controlled stretching machine (L. MONNERIE), ESPCI, Paris.

[4] Monnerie, L., Private discussion.

[5] De Gennes, P. G., J. Chem. Phys. 55 (1971) 572 and also, Scaling Concepts in Polymer Physics, Ch. VIII (Cornell University Press, London) 1979.

[6] Doï, M., Edwards, S. F., J. Chem. Soc. Faraday Trans. 274 (1978) 1789, 1802, 1818.

[7] Ferry, J. D., Viscoelastic properties of polymers (Wiley, New York) 1970. 